\title{
Chronic Hyperkalemia Impairs Ammonium Transport and Accumulation in the Inner Medulla of the Rat
}

\author{
Thomas D. DuBose, Jr., and David W. Good \\ Division of Nephrology, Departments of Internal Medicine, Physiology and Biophysics, \\ University of Texas Medical Branch, Galveston, Texas 77550
}

\begin{abstract}
Previously we demonstrated in rats that chronic hyperkalemia had no effect on ammonium secretion by the proximal tubule in vivo but that high $\mathrm{K}^{+}$concentrations inhibited ammonium absorption by the medullary thick ascending limb in vitro. These observations suggested that chronic hyperkalemia may reduce urinary ammonium excretion through effects on medullary transport events. To examine directly the effects of chronic hyperkalemia on medullary ammonium accumulation and collecting duct ammonium secretion, micropuncture experiments were performed in the inner medulla of Munich-Wistar rats pair fed a control or high-K ${ }^{+}$diet for 7-13 d. In situ $\mathrm{pH}$ and total ammonia concentrations were measured to calculate $\mathrm{NH}_{3}$ concentrations for base and tip collecting duct and vasa recta. Chronic $\mathrm{K}^{+}$loading was associated with significant systemic metabolic acidosis and a $\mathbf{4 0} \%$ decrease in urinary ammonium excretion. In control rats, $15 \%$ of excreted ammonium was secreted between base and tip collecting duct sites. In contrast, no net transport of ammonium was detected along the collecting duct in high- $\mathrm{K}^{+}$rats. The decrease in collecting duct ammonium secretion in hyperkalemia was associated with a decrease in the $\mathrm{NH}_{3}$ concentration difference between vasa recta and collecting duct. The fall in the $\mathrm{NH}_{3}$ concentration difference across the collecting duct in high- $\mathrm{K}^{+}$rats was due entirely to a decrease in $\left[\mathrm{NH}_{3}\right]$ in the medullary interstitial fluid, with no change in $\left[\mathrm{NH}_{3}\right]$ in the collecting duct. These results indicate that impaired accumulation of ammonium in the medullary interstitium, secondary to inhibition of ammonium absorption in the medullary thick ascending limb, may play an important role in reducing collecting duct ammonium secretion and urinary ammonium excretion during chronic hyperkalemia. (J. Clin. Invest. 1992.90:1443-1449.) Key words: collecting duct acidification - countercurrent multiplication - hyperkalemic metabolic acidosis $\bullet$ loop of Henle $\bullet$ urinary ammonia excretion
\end{abstract}

Results of these experiments were reported in preliminary form at the 22nd Annual Meeting of the American Society of Nephrology ( 1990. Kidney Int. 37:535).

Dr. DuBose's present address is Division of Nephrology, Department of Internal Medicine, University of Texas Health Science Center at Houston, 6431 Fannin, MSB 4.136, Houston, TX 77030.

Address reprint requests to Dr. Good, Division of Nephrology, Room 4.200, John Sealy Hospital, E62, University of Texas Medical Branch, Galveston, TX 77550.

Received for publication 29 January 1992 and in revised form 29 April 1992.

J. Clin. Invest.

(c) The American Society for Clinical Investigation, Inc. $0021-9738 / 92 / 10 / 1443 / 07 \quad \$ 2.00$

Volume 90, October 1992, 1443-1449

\section{Introduction}

Changes in systemic potassium balance have an important influence on urinary net acid excretion, predominantly through effects on urinary ammonium excretion (1-3). ${ }^{1}$ Potassium retention and clinical hyperkalemia are associated with a decrease in urinary ammonium excretion that is thought to contribute to the metabolic acidosis that accompanies a variety of pathologic conditions, such as mineralocorticoid deficiency and chronic renal insufficiency (2-8). Based on the observations that an increase in extracellular potassium concentration decreased ammonium synthesis by renal cortical slices, renal cortical tubule suspensions, and isolated, perfused proximal tubules (9-11), it had generally been assumed that the decrease in urinary ammonium excretion with hyperkalemia was the result of a decrease in ammonium production and secretion by the proximal tubule. Recently, however, we have shown that dietary $\mathrm{K}^{+}$loading sufficient to cause chronic hyperkalemia in rats markedly reduced renal ammonium production and urinary ammonium excretion, with no significant effect on either net ammonium secretion by or ammonium delivery out of the proximal convoluted tubule (12). These findings suggested that the decrease in ammonium excretion in hyperkalemia may be the result of an impaired ability to transfer the ammonium secreted by the proximal tubules to the final urine.

A possible mechanism by which hyperkalemia could impair transfer of ammonium to the urine was identified in studies of isolated, perfused medullary thick ascending limbs from rats. Active absorption of $\mathrm{NH}_{4}^{+}$by the medullary thick ascending limb plays an important role in transferring the ammonium produced by proximal tubules from loops of Henle to collecting ducts in the renal medulla $(13,14)$. Specifically, medullary thick ascending limb $\mathrm{NH}_{4}^{+}$absorption drives an ammonium countercurrent multiplier that results in high concentrations of $\mathrm{NH}_{3}$ in the medullary interstitial fluid and generates the transepithelial $\mathrm{NH}_{3}$ concentration difference that drives secretion of ammonium into medullary collecting ducts (1315). Active absorption of $\mathrm{NH}_{4}^{+}$by the medullary thick ascending limb in vitro was markedly inhibited when the $\mathrm{K}^{+}$concentration in perfusion and bath solutions was increased over the physiological range $(16,17)$. Because medullary $\mathrm{K}^{+}$levels are greatly increased with dietary $\mathrm{K}^{+}$loading (18), we proposed that chronic hyperkalemia may diminish urinary ammonium excretion by inhibiting $\mathrm{NH}_{4}^{+}$absorption in the medullary thick ascending limb and impairing transfer of ammonium to medullary collecting ducts $(16,17)$.

1. In this article, as in previous papers (see references 12 and 13), the terms ammonium and total ammonia are used interchangeably to indicate the sum of $\mathrm{NH}_{4}^{+}$and $\mathrm{NH}_{3}$. When mechanisms of ammonium transport are discussed, the chemical formulas $\mathrm{NH}_{4}^{+}$and $\mathrm{NH}_{3}$ are used to indicate the particular species transported. 
The present study was designed to examine directly whether chronic hyperkalemia alters the transfer of ammonium to collecting ducts in the renal medulla. Micropuncture experiments were performed to investigate the effects of chronic hyperkalemia on ammonium accumulation and collecting duct ammonium secretion in the inner medulla of the rat in vivo. The results show that chronic $\mathrm{K}^{+}$loading reduces net secretion of ammonium into the medullary collecting ducts, and that the decrease in the driving force for ammonium secretion is the result of a decrease in accumulation of ammonium in the medullary interstitial fluid.

\section{Methods}

Male Munich-Wistar rats weighing $100-180 \mathrm{~g}$ were placed on a vitamin-fortified $\mathrm{K}^{+}$-deficient diet (AIN-76, modified; ICN Biochemicals, Cleveland, $\mathrm{OH}$ ) and divided into two groups based on dietary $\mathrm{K}^{+}$supplementation. Control (normal $\mathrm{K}^{+}$diet) rats received the basic diet supplemented to contain $0.6 \mathrm{~g} \mathrm{KCl} / 100 \mathrm{~g}$ food. High- $\mathrm{K}^{+}$rats received the basic diet supplemented with $15 \mathrm{~g} \mathrm{KCl} / 100 \mathrm{~g}$ food. Each group received the diet for 7-13 $d$ before experiments. Rats were pair-fed as previously described (12) to insure equivalent food intake and similar weight gain. Both groups had free access to tap water throughout the treatment period.

Anesthesia was induced by intraperitoneal injection of Inactin (Byk-Gulden, Constance, FRG), $100 \mathrm{mg} / \mathrm{kg}$ body weight. The rats were maintained at $37^{\circ} \mathrm{C}$ on a heated table and prepared surgically for micropuncture of the exposed renal papilla as previously described (15, 19). The left kidney was exposed through a flank incision, immobilized in a Lucite cup with $3 \%$ agar in saline, and bathed continuously with mineral oil warmed to $37^{\circ} \mathrm{C}$. Surgical fluid losses were replaced in control rats by intravenous administration of saline-bicarbonate ( 120 $\mathrm{mM} \mathrm{NaCl}, 25 \mathrm{mM} \mathrm{NaHCO}_{3}, 4 \mathrm{mM} \mathrm{KCl}$ ) equal to $1 \%$ body weight over $15 \mathrm{~min}$. This solution was then infused at a rate of $1.5 \%$ body $\mathrm{wt} / \mathrm{h}$ for the duration of the experiment. High- $\mathrm{K}^{+}$rats were treated identically except that the infusion solution contained $140 \mathrm{mM} \mathrm{NaCl}$ and 10 $\mathrm{mM} \mathrm{KCl}$. After surgery was completed, $\left[\right.$ methoxy $\left.-{ }^{3} \mathrm{H}\right]$ inulin was added to the infusion solution and administered at a rate of $150 \mu \mathrm{Ci} / \mathrm{h}$.

Clearance measurements and papillary micropuncture were begun $1 \mathrm{~h}$ after the start of the inulin infusion. Urine from the right, untouched kidney was collected into preweighed tubes via a bladder catheter for determination of whole kidney glomerular filtration rate, urine $\mathrm{pH}$, and electrolyte excretion rates. Arterial blood samples were collected to bracket urine collection periods. Tubule fluid from the base and tip of the papillary collecting duct and blood from the vasa recta capillaries were collected using sharpened micropipets as previously described $(15,19)$. Vasa recta samples generally were collected from a point midway between the base and tip collecting duct sites. In situ pH for base and tip collecting duct and vasa recta capillaries was measured with single-barreled glass-membrane microelectrodes (15). The length of the exposed papilla between base and tip collecting duct sites was measured at the end of experiments with an ocular micrometer.

Analysis. Arterial blood acid-base values and concentrations of $\mathrm{Na}^{+}$and $\mathrm{K}^{+}$in arterial plasma and bladder urine were measured using standard techniques $(12,15)$. Urine $\mathrm{pH}$ was measured with a microcombination pH electrode (Microelectrodes, Inc., Londonderry, NH). Urine volume was determined by weighing. Inulin radioactivity in arterial plasma, urine, and micropuncture samples was quantitated by liquid scintillation counting using Ready-Solv (Beckman Instruments, Inc., Palo Alto, CA). The radioactivity of micropuncture samples was determined on a volume of each sample measured in a calibrated constant-bore capillary. Vasa recta plasma was evaluated for contamination with collecting duct fluid or papillary urine as previously described (15). Samples were discarded if the vasa recta inulin concentration exceeded that in systemic plasma by $>5 \%$ of collecting duct inulin concentration. Total ammonia concentration in arterial plasma, urine, and papillary micropuncture samples was measured by microfluorometry using the glutamate dehydrogenase reaction as described previously in detail $(15,20)$.

Calculations. Right kidney glomerular filtration rate (GFR) was calculated as the product of urine flow rate and urine/arterial plasma inulin concentration ratio. Sodium, potassium, and ammonium excretion rates were calculated as the products of urine flow rate and ion concentration. To obtain a quantitative estimate of ammonium transport along the collecting duct, absolute rates of ammonium delivery (Am, $\mu \mathrm{mol} / \mathrm{min}$ ) to base and tip collecting duct sites were calculated as $\mathrm{A} \dot{\mathrm{m}}=([\mathrm{Am}] \cdot \mathrm{GFR}) /(\mathrm{TF} / \mathrm{P})_{\text {In }}$, where $[\mathrm{Am}]$ is total ammonia concentration and $(T F / P)_{\text {In }}$ is tubule fluid/arterial plasma inulin concentration ratio. ${ }^{2}$ The net rate of ammonium transport along the collecting duct in individual rats was calculated as the difference between base and tip delivery rates.

Concentrations of $\mathrm{NH}_{3}$ in base and tip collecting duct and vasa recta were determined by measuring total ammonia concentrations and in situ $\mathrm{pH}$ values in different structures of the same animal. A mean $\mathrm{pH}$ and total ammonia concentration was determined for each structure from the results of one to three measurements in each rat. $\mathrm{NH}_{3}$ concentrations for base and tip collecting duct and vasa recta plasma were calculated from mean $\mathrm{pH}$ values and mean total ammonia concentrations as $\left[\mathrm{NH}_{3}\right]=[\mathrm{Am}] /\left(1+10^{\mathrm{pKa} \mathbf{p}^{\prime} \mathrm{pH}}\right)$, where $\mathrm{pKa}^{\prime}$ is the negative $\log$ of the dissociation constant for ammonium. $\mathrm{pKa}^{\prime}$ values calculated in our previous study for medullary structures of control rats were: base collecting duct 9.049 , tip collecting duct 9.055 , vasa recta 9.070 (15). These values were used in the present study for both control and high- $\mathrm{K}^{+}$rats. Because $\mathrm{pKa}^{\prime}$ is dependent on ionic strength, this analysis assumes that the ionic strength of medullary structures is similar in control and high- $\mathrm{K}^{+}$rats. In support of this assumption: $(a) \mathrm{Na}^{+}$ and $\mathrm{NH}_{4}^{+}$concentrations are reduced while $\mathrm{K}^{+}$concentration is increased at the base and tip of the collecting duct of high- $\mathrm{K}^{+}$rats, resulting in total cation concentrations and osmolalities that are within $\sim 20 \%$ of values in controls $(18,21,22$; and see Table III $)$, and $(b)$ $\mathrm{Na}^{+}$concentration, $\mathrm{K}^{+}$concentration, and osmolality differ by $<15 \%$ in vasa recta plasma of control and high- $\mathrm{K}^{+}$rats (18). As discussed previously (15), a small over- or underestimate of ionic strength has negligible impact on calculated $\mathrm{NH}_{3}$ concentrations in medullary structures. For each medullary structure, $\mathrm{NH}_{3}$ concentrations determined in individual rats were averaged to obtain the group means presented in Table IV (q.v.). Differences in $\mathrm{NH}_{3}$ concentration were evaluated by making paired comparisons of $\mathrm{NH}_{3}$ concentrations determined in different structures in the same animal. Differences between means were evaluated using the $t$ test for paired or unpaired data, as appropriate. A $P$ value of $<0.05$ was regarded as statistically significant.

\section{Results}

Body weight, arterial blood acid-base values, and plasma electrolytes are summarized in Table I. Mean body weight at the time of experiments did not differ in control and high- $\mathrm{K}^{+}$rats (Table I). Body weight measured before placement on the experimental diets $\left(125 \pm 10\right.$, control vs. $133 \pm 9 \mathrm{~g}$, high-K ${ }^{+}$; NS) and total weight gain over the 7-13-d dietary treatment period ( $25 \pm 5$, control vs. $16 \pm 4 \mathrm{~g}$, high- $\mathrm{K}^{+}$; NS) also did not differ in the two groups. In rats on the high- $\mathrm{K}^{+}$diet, arterial blood $\mathrm{pH}$ and $\mathrm{HCO}_{3}^{-}$concentration were reduced and plasma $\mathrm{K}^{+}$concentration was increased compared with controls (Table I). Plasma $\mathrm{Na}^{+}$and total ammonia concentrations did not differ in the two groups.

Renal function data for the right, untouched kidney are summarized in Table II. Glomerular filtration rate and $\mathrm{Na}^{+}$

\footnotetext{
2. Abbreviation used in this paper: $(\mathrm{TF} / \mathrm{P})_{\mathrm{In}}$, tubule fluid/arterial plasma inulin concentration ratio.
} 
Table I. Body Weight and Arterial Blood Measurements

\begin{tabular}{|c|c|c|c|c|c|c|c|}
\hline & \multirow{2}{*}{$\begin{array}{c}\text { Body } \\
\text { wt }\end{array}$} & \multicolumn{3}{|c|}{ Blood } & \multicolumn{3}{|c|}{ Plasma } \\
\hline & & $\mathrm{pH}$ & $\mathrm{PCO}_{2}$ & $\mathrm{HCO}_{3}^{-}$ & {$\left[\mathrm{Na}^{+}\right]$} & {$\left[\mathrm{K}^{+}\right]$} & [Am] \\
\hline & $g$ & $U$ & $m m H g$ & $m M$ & $m M$ & $m M$ & $m M$ \\
\hline Control (11) & $150 \pm 6$ & $7.30 \pm 0.01$ & $42.3 \pm 0.7$ & $20.0 \pm 0.4$ & $146 \pm 1$ & $4.5 \pm 0.1$ & $0.07 \pm 0.01$ \\
\hline High $\mathrm{K}^{+}(10)$ & $149 \pm 6$ & $7.26 \pm 0.02$ & $39.6 \pm 1.5$ & $17.0 \pm 0.4$ & $145 \pm 1$ & $6.6 \pm 0.4$ & $0.08 \pm 0.01$ \\
\hline$P$ & NS & $<0.05$ & NS & $<0.005$ & NS & $<0.001$ & NS \\
\hline
\end{tabular}

Values are means \pm SE. Numbers in parentheses are numbers of rats. Am, total ammonia. $P$ values compare control vs. high $\mathrm{K}^{+}$(unpaired $t$ test). NS, no significant difference.

excretion did not differ significantly in control and high- $\mathrm{K}^{+}$ rats. Urine $\mathrm{pH}$, urine flow rate, and $\mathrm{K}^{+}$excretion were increased and urine ammonium concentration was reduced in high- $\mathrm{K}^{+}$rats compared with controls. Urinary ammonium excretion was reduced by $40 \%$ in the high- $\mathrm{K}^{+}$rats (Table II). These results are similar to those obtained in our previous study in which rats received the same dietary treatments but urine was collected from the micropunctured kidney via a ureteral cannula (12).

Micropuncture values for collecting duct and vasa recta. Micropuncture data for the base and tip of the collecting duct and vasa recta are summarized in Table III. The length of the exposed papilla between base and tip collecting duct was $2.8 \pm 0.2$ $\mathrm{mm}$ in high- $\mathrm{K}^{+}$rats and $2.5 \pm 0.1 \mathrm{~mm}$ in controls $(P=\mathrm{NS}) . \mathrm{pH}$ fell along the collecting duct in control rats but did not differ at base and tip collecting duct sites in high- $\mathrm{K}^{+}$animals. $\mathrm{pH}$ values measured at the base and tip of the collecting duct were higher in high- $\mathrm{K}^{+}$rats than in controls (Table III). Ammonium concentration and $\mathrm{TF} / \mathrm{P}_{\mathrm{In}}$ increased between the base and tip of the collecting duct in both groups of rats. In high- $\mathrm{K}^{+}$rats, the ammonium concentration and the $\mathrm{TF} / \mathrm{P}_{\mathrm{In}}$ at base and tip collecting duct were reduced compared with controls. The ammonium concentration in vasa recta plasma also was reduced in the high- $\mathrm{K}^{+}$animals (Table III).

To assess net transport of ammonium along the collecting duct, changes in ammonium concentration between base and tip collection sites were factored for net water movement by dividing by $T F / P_{I n}$ values. The resulting ratio $[[\mathrm{Am}] /(\mathrm{TF} /$ $\left.P)_{\text {In }}\right]$ is a measure of the relative amount of ammonium delivered to base and tip collecting duct sites. The results are shown in Fig. 1. In control rats, $[\mathrm{Am}] /(\mathrm{TF} / \mathrm{P})_{\text {In }}$ increased significantly between base and tip, indicating that there was net secretion of ammonium along the terminal portion of the inner medullary collecting duct. The $[\mathrm{Am}] /(\mathrm{TF} / \mathrm{P})_{\text {In }}$ ratio rose from $1.03 \pm 0.07$ at the collecting duct base to $1.18 \pm 0.07$ at the tip $(P$
$<0.025$ ), indicating that $\sim 15 \%$ of excreted ammonium was secreted along the collecting duct under control conditions. In contrast, $[\mathrm{Am}] /(\mathrm{TF} / \mathrm{P})_{\text {In }}$ did not differ significantly at the base and tip collecting duct in high- $\mathrm{K}^{+}$rats (Fig. 1). Thus, there was no detectable net transport of ammonium along the collecting duct during chronic hyperkalemia. Absolute rates of ammonium transport along the collecting duct, calculated from base and tip $[\mathrm{Am}] /(\mathrm{TF} / \mathrm{P})_{\text {In }}$ values and right kidney GFR (see Methods), are shown for individual rats in Fig. 2. In control rats, net secretion of ammonium occurred at a rate of $-127 \pm 41$ $\mu \mathrm{mol} / \mathrm{min}(n=11)$. In high-K ${ }^{+}$rats, the net ammonium transport rate $(57 \pm 39 \mu \mathrm{mol} / \mathrm{min}, n=10)$ differed significantly from that observed in controls (Fig. 2) but did not differ significantly from zero. Thus, net secretion of ammonium along the collecting duct was abolished by chronic potassium loading.

$\mathrm{NH}_{3}$ concentrations in inner medulla. To determine whether the reduction in collecting duct ammonium secretion in high- $\mathrm{K}^{+}$rats was associated with a decrease in the $\mathrm{NH}_{3}$ concentration difference across the collecting duct, $\mathrm{NH}_{3}$ concentrations were determined at the base and tip of the collecting duct and in vasa recta plasma in individual rats. The results are summarized in Table IV (mean values) and Fig. 3 (individual data). In both control and high-K ${ }^{+}$rats, the $\mathrm{NH}_{3}$ concentration at the collecting duct base did not differ from that at the collecting duct tip (Table IV, left). Thus, a mean collecting duct $\mathrm{NH}_{3}$ concentration was calculated for each rat as the arithmetic mean of the base and tip values ( $C D$, Table IV). Neither the mean collecting duct $\mathrm{NH}_{3}$ concentration nor the $\mathrm{NH}_{3}$ concentrations measured at the base and tip differed significantly in control and high- $\mathrm{K}^{+}$rats. In contrast, the $\mathrm{NH}_{3}$ concentration in vasa recta plasma was significantly reduced in the high$\mathrm{K}^{+}$animals (Table IV). The fall in vasa recta $\mathrm{NH}_{3}$ concentration was the result of a decrease in total ammonia concentration, with no change in vasa recta pH (Table III).

To assess $\mathrm{NH}_{3}$ concentration differences across the collect-

Table II. Right Whole-Kidney Data

\begin{tabular}{|c|c|c|c|c|c|c|c|}
\hline & \multirow[b]{2}{*}{ GFR } & \multicolumn{3}{|c|}{ Urine analysis } & \multicolumn{3}{|c|}{ Excretion rate } \\
\hline & & pH & Flow rate & [Am] & $\mathrm{Na}^{+}$ & $\mathrm{K}^{+}$ & Am \\
\hline & $\mathrm{ml} / \mathrm{min}$ & $U$ & $\mu l / m i n$ & $m M$ & & $\mu \mathrm{mol} / \mathrm{min}$ & \\
\hline Control (11) & $0.84 \pm 0.05$ & $5.31 \pm 0.03$ & $5.4 \pm 0.3$ & $217 \pm 21$ & $0.36 \pm 0.08$ & $1.0 \pm 0.1$ & $1.1 \pm 0.1$ \\
\hline High $\mathrm{K}^{+}(10)$ & $0.75 \pm 0.07$ & $5.73 \pm 0.10$ & $9.4 \pm 0.9$ & $76 \pm 7$ & $0.29 \pm 0.04$ & $3.1 \pm 0.4$ & $0.67 \pm 0.04$ \\
\hline$P$ & NS & $<0.001$ & $<0.001$ & $<0.001$ & NS & $<0.001$ & $<0.001$ \\
\hline
\end{tabular}

Values are means \pm SE. Numbers in parentheses are numbers of rats. GFR, glomerular filtration rate. Am and $P$ values as in Table I. 


\begin{tabular}{|c|c|c|c|c|c|c|c|c|}
\hline & \multicolumn{3}{|c|}{ Base collecting duct } & \multicolumn{3}{|c|}{ Tip collecting duct } & \multicolumn{2}{|c|}{ Vasa recta } \\
\hline & pH & [Am] & $(\mathrm{TF} / \mathrm{P})_{\mathrm{ln}}$ & pH & [Am] & $(T F / P)_{h n}$ & $\mathrm{pH}$ & [Am] \\
\hline & $U$ & $m M$ & & $U$ & $m M$ & & $U$ & $m M$ \\
\hline Control & $5.74 \pm 0.04(8)$ & $66.8 \pm 7.7(10)$ & $66.3 \pm 7.1(10)$ & $5.60 \pm 0.03^{*}(10)$ & $139.2 \pm 19.5^{*}(10)$ & $119.9 \pm 17.3^{*}(10)$ & $7.28 \pm 0.04(8)$ & $8.4 \pm 0.8(9)$ \\
\hline High $\mathrm{K}^{+}$ & $6.06 \pm 0.06(10)$ & $44.4 \pm 5.4(10)$ & $37.8 \pm 3.7(10)$ & $6.01 \pm 0.03(10)$ & $64.0 \pm 8.8^{*}(10)$ & $58.1 \pm 6.6^{*}(10)$ & $7.27 \pm 0.05(7)$ & $6.0 \pm 0.5(6)$ \\
\hline$P$ & $<0.001$ & $<0.05$ & $<0.005$ & $<0.001$ & $<0.005$ & $<0.005$ & NS & $<0.05$ \\
\hline
\end{tabular}

Values are means \pm SE. Numbers in parentheses are numbers of rats. [Am], total ammonia concentration in collecting duct fluid or vasa recta plasma. $(\mathrm{TF} / \mathrm{P})_{\mathrm{ln}}$, tubule fluid/arterial plasma inulin concentration ratio. * Tip collecting duct value significantly different from base (paired $t$ test). $P$ values as in Table $\mathrm{I}$.

ing duct, the $\mathrm{NH}_{3}$ concentration in vasa recta plasma (a measure of the $\mathrm{NH}_{3}$ concentration in medullary interstitial fluid) was compared with the mean collecting duct $\mathrm{NH}_{3}$ concentration determined in the same animal. The results of these paired experiments are shown in Fig. 3 and in Table IV (right). In both control and high- $\mathrm{K}^{+}$rats, the $\mathrm{NH}_{3}$ concentration in the vasa recta was significantly greater than the mean $\mathrm{NH}_{3}$ concentration in the collecting duct (Fig. 3). The mean difference in $\mathrm{NH}_{3}$ concentration between the vasa recta and collecting duct was significantly reduced in the high- $\mathrm{K}^{+}$rats compared with controls $\left(\Delta\left[\mathrm{NH}_{3}\right]\right.$, Table IV). As shown in Fig. 3 and Table IV, the decrease in the $\mathrm{NH}_{3}$ concentration difference across the collecting duct in high- $\mathrm{K}^{+}$rats was due to a fall in $\mathrm{NH}_{3}$ concentration in the medullary interstitium, with no change in $\mathrm{NH}_{3}$ concentration in the medullary collecting duct. The $\mathrm{NH}_{3}$ concentration in the collecting duct remains unchanged in the high $\mathrm{K}^{+}$rats, despite a decrease in collecting duct total ammonia concentration, because the fall in total ammonia concentration is offset by an increase in collecting duct $\mathrm{pH}$ (Table III).

\section{Discussion}

A decrease in urinary ammonium excretion secondary to hyperkalemia is believed to play an important causative role in
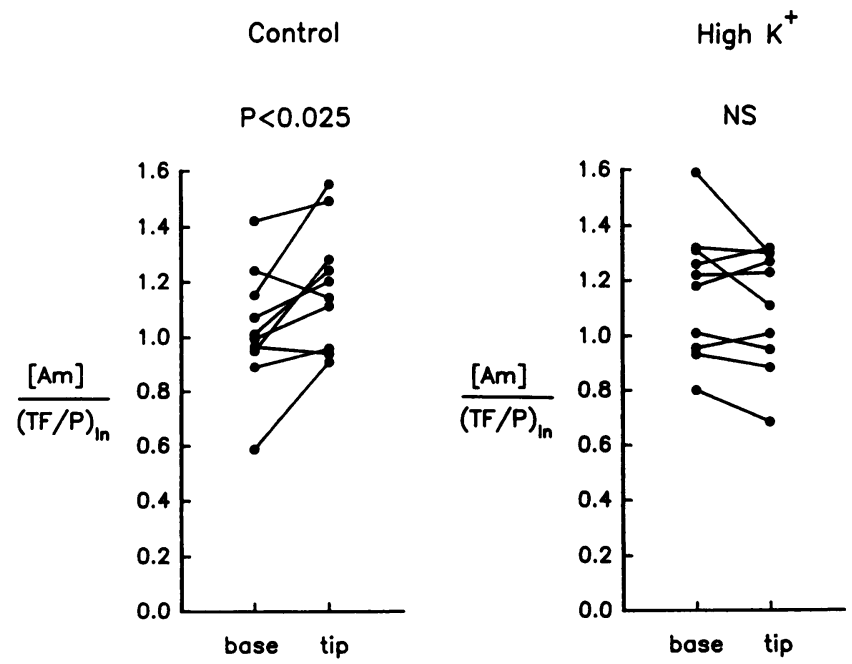

Figure 1. $[\mathrm{Am}] /(\mathrm{TF} / \mathrm{P})_{\text {In }}$ values for base and tip collecting duct of control and high- $\mathrm{K}^{+}$rats. All values are in millimolar. Data points $(\bullet)$ are mean values for individual rats. Lines connect paired values obtained in the same rat. $P$ values are for base vs. tip (paired $t$ test); NS, no significant difference. the metabolic acidosis that accompanies a variety of clinical disorders, such as renal insufficiency and type 4 renal tubular acidosis (2-8). The present study was designed to examine directly whether hyperkalemia reduces urinary ammonium excretion through effects on ammonium transport processes in the renal medulla. The results demonstrate that chronic hyperkalemia has several important medullary effects. First, dietary potassium loading was associated with a decrease in accumulation of ammonium in the renal medullary interstitium, as evidenced by a significant decrease in both $\mathrm{NH}_{3}$ and $\mathrm{NH}_{4}^{+}$concentrations in vasa recta plasma (Tables III and IV, Fig. 3). Second, the $\mathrm{NH}_{3}$ concentration difference between medullary interstitial fluid and inner medullary collecting duct was reduced in hyperkalemia (Table IV, Fig. 3), indicating a reduction in the driving force for entry of $\mathrm{NH}_{3}$ into the collecting duct lumen. Third, the fall in the $\mathrm{NH}_{3}$ concentration difference

\section{$P<0.025$}

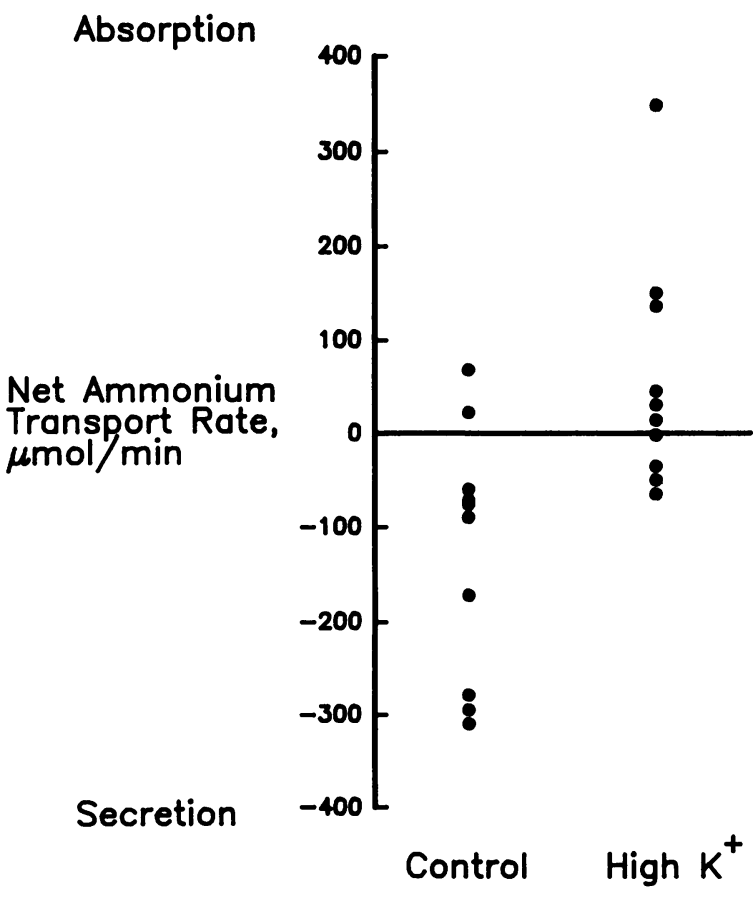

Figure 2. Net rates of ammonium transport along the collecting duct of control and high- $\mathrm{K}^{+}$rats. Rates were calculated as described in Methods. Mean values are given in Results. Collecting duct length was $2.5 \pm 0.1 \mathrm{~mm}$ in controls and $2.8 \pm 0.2 \mathrm{~mm}$ in high- $\mathrm{K}^{+}(P=\mathrm{NS})$. Data points $(\bullet)$ are for individual rats. $P$ value is for control vs. high$\mathrm{K}^{+}$(unpaired $t$ test). 


\begin{tabular}{|c|c|c|c|c|c|}
\hline & \multicolumn{2}{|c|}{ Collecting duct } & \multirow[b]{2}{*}{ Vasa recta } & \multirow[b]{2}{*}{$\overline{\mathrm{CD}}$} & \multirow[b]{2}{*}{$\Delta\left[\mathrm{NH}_{3}\right]$} \\
\hline & Base & Tip & & & \\
\hline & $\mu M$ & $\mu M$ & $\mu M$ & $\mu M$ & $\mu M$ \\
\hline Control (8) & $42 \pm 9$ & $47 \pm 10$ & $135 \pm 17$ & $44 \pm 9$ & $92 \pm 19 *$ \\
\hline High $\mathrm{K}^{+}(6)$ & $48 \pm 10$ & $51 \pm 9$ & $90 \pm 9$ & $50 \pm 8$ & $40 \pm 8^{*}$ \\
\hline$P$ & & & $<0.05$ & NS & $<0.05$ \\
\hline
\end{tabular}

Values are means \pm SE for paired experiments in which vasa recta, base collecting duct, and tip collecting duct $\mathrm{NH}_{3}$ concentrations were determined in individual rats. $\overline{\mathrm{CD}}$, mean collecting duct $\mathrm{NH}_{3}$ concentration determined by averaging base and tip concentrations; $\Delta\left[\mathrm{NH}_{3}\right]$, difference between vasa recta $\mathrm{NH}_{3}$ concentration and $\overline{\mathrm{CD}}$ in paired experiments. NS, no significant difference between base and tip $\mathrm{NH}_{3}$ concentrations (paired $t$ test). ${ }^{*} \Delta\left[\mathrm{NH}_{3}\right]$ significantly different from zero. Numbers in parentheses and $P$ values as in Table $\mathrm{I}$.

across the collecting duct was associated with a marked decrease in collecting duct ammonium secretion (Figs. 1 and 2). Fourth, the decrease in the $\mathrm{NH}_{3}$ concentration difference across the collecting duct was due entirely to the fall in $\mathrm{NH}_{3}$ concentration in the medullary interstitial fluid, with no change in $\mathrm{NH}_{3}$ concentration in the collecting duct lumen. Taken together, these results indicate that an impaired ability to accumulate ammonium in the medullary interstitial fluid plays an important role in reducing collecting duct ammonium secretion and urinary ammonium excretion during chronic hyperkalemia. These effects of hyperkalemia on medullary ammonium transport are discussed below in the context of our current understanding of the mechanisms of renal ammonium excretion.

Ammonium excreted in the urine is produced predominantly in the renal cortex in the proximal tubules and secreted into the proximal tubule lumen $(13,23)$. Ammonium delivered out of the proximal tubules is then transferred to the final urine via a pathway in the renal medulla that involves countercurrent multiplication of ammonium in the loop of Henle, accumulation of ammonium to high concentrations in the medullary interstitial fluid, and secretion of ammonium into the medullary collecting ducts $(13,14)$. Changes in the rate of urinary ammonium excretion may be accomplished through regulation of proximal tubule ammonium production and secretion and/or through regulation of the medullary transport processes that transfer ammonium to the final urine. The effects of systemic potassium balance on renal ammonium excretion traditionally have been attributed to effects of potassium on production and secretion of ammonium by the proximal tubules (1-7, 9-11). However, we demonstrated recently in the rat in vivo that chronic hyperkalemia markedly reduced urinary ammonium excretion but had no effect on net secretion of ammonium by the proximal convoluted tubule (12). Because delivery of ammonium from the proximal convoluted tubule to the loop segment was similar in control and high- $\mathrm{K}^{+}$ rats, we suggested that the major regulatory effect of chronic hyperkalemia may be to diminish the transfer of ammonium from loops of Henle to collecting ducts in the renal medulla (12). The present study provides direct support for this view, indicating that both medullary ammonium accumulation and collecting duct ammonium secretion are impaired by dietary $\mathrm{K}^{+}$loading.

Ammonium accumulates in the renal medulla to concentrations much greater than those in the renal cortex as the result of a countercurrent system in the loop of Henle that is analogous to the countercurrent multiplier for $\mathrm{NaCl}(13,14)$. The energy source for countercurrent multiplication of ammonium is active absorption of $\mathrm{NH}_{4}^{+}$by the thick ascending limb (13, $14,17,24,25)$. In support of this view, furosemide has been shown to abolish both net ammonium absorption by the thick ascending limb in vitro $(24,26)$ and the corticomedullary gradient for ammonium in vivo (27). Changes in medullary ammonium accumulation could result from changes in ammonium transport processes in the loop of Henle and/or from changes in proximal tubule ammonium secretion that alter the rate at which ammonium is delivered to the countercurrent multiplier. ${ }^{3}$ Dietary $\mathrm{K}^{+}$loading in rats had no effect on delivery of ammonium out of the proximal convoluted tubule (12). Thus, the decrease in medullary ammonium accumulation in chronic hyperkalemia likely is the result of an alteration in ammonium transport by the loop of Henle.

A mechanism by which hyperkalemia could impair loop ammonium transport and medullary ammonium accumulation was identified previously in studies with isolated, perfused medullary thick ascending limbs $(16,17)$. Absorption of $\mathrm{NH}_{4}^{+}$ by the thick ascending limb occurs predominantly by secondary active transport, mediated by substitution of $\mathrm{NH}_{4}^{+}$for $\mathrm{K}^{+}$ on the apical membrane $\mathrm{Na}^{+}-\mathrm{K}^{+}-2 \mathrm{Cl}^{-}$cotransporter $(14,16$, $17,25,28)$. Increasing potassium concentration from 4 to 24 $\mathrm{mM}$ in luminal and peritubular solutions markedly inhibits active $\mathrm{NH}_{4}^{+}$absorption in the rat medullary thick ascending limb in vitro, most likely due to competition between $\mathrm{NH}_{4}^{+}$and $\mathrm{K}^{+}$on $\mathrm{Na}^{+}-\mathrm{K}^{+}-2 \mathrm{Cl}^{-}$cotransport system $(16,17)$. Potassium concentrations much greater than those observed to inhibit medullary thick ascending limb $\mathrm{NH}_{4}^{+}$absorption in vitro are present in loop of Henle and medullary interstitial fluid during dietary potassium loading in vivo (18). Consequently, an ef-

3. Several observations support the view that the fall in medullary interstitial ammonium concentration in the high $\mathrm{K}^{+}$rats is unlikely to be the result of a generalized medullary washout: $(a)$ total renal blood flow and total renal plasma flow were unaffected by dietary $\mathrm{K}^{+}$loading $(12) ;(b)$ we observed no significant difference in vasa recta to arterial plasma inulin concentration ratio in control and high- $\mathrm{K}^{+}$rats $(1.9 \pm 0.2$ [9], control vs. $2.2 \pm 0.2$ [6], high-K ${ }^{+} ; P=\mathrm{NS}$ ); (c) Battilana et al. (18) found no significant effect of chronic dietary $\mathrm{K}^{+}$loading on vasa recta plasma osmolality, despite an increase in urine flow rate and a decrease in inner medullary collecting duct $T F / P_{I n}$ ratios in the high $\mathrm{K}^{+}$group similar to those observed in the present study. 

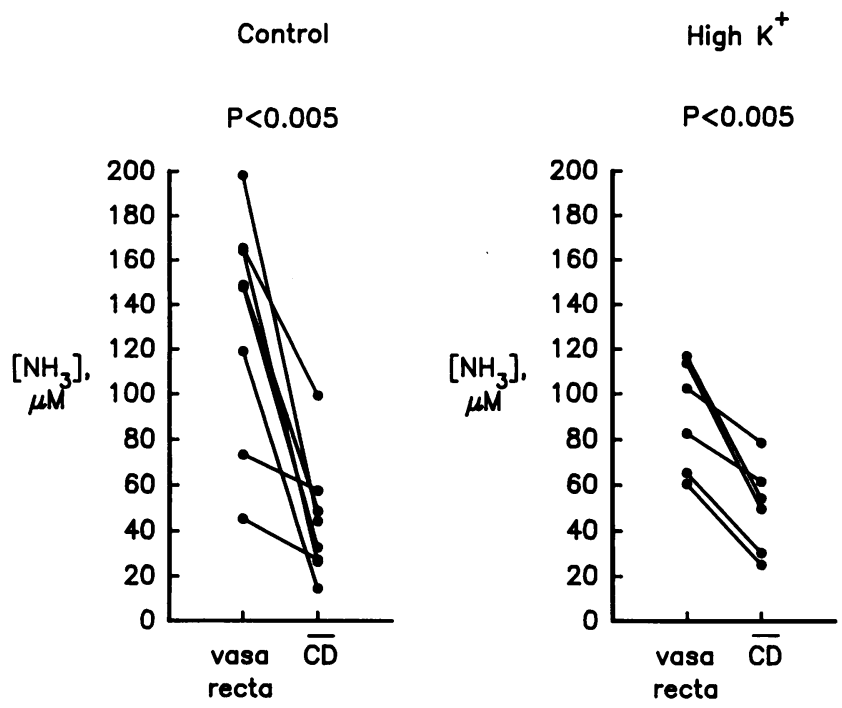

Figure 3. Comparison of $\mathrm{NH}_{3}$ concentration in vasa recta with mean $\mathrm{NH}_{3}$ concentration in collecting duct $(\overline{C D})$ in control and high- $\mathrm{K}^{+}$ rats. $\overline{\mathrm{CD}}$ was calculated as the arithmetic mean of base and tip values (see text). Data points $(\bullet)$ are $\mathrm{NH}_{3}$ concentrations determined in individual rats from measured $\mathrm{pH}$ and total ammonia concentrations. Lines connect paired values obtained in the same rat. $P$ values are for vasa recta vs. $\overline{\mathrm{CD}}$ (paired $t$ test).

fect of elevated medullary $\mathrm{K}^{+}$levels to impair medullary thick ascending limb $\mathrm{NH}_{4}^{+}$absorption and ammonium countercurrent multiplication could account for the reduced medullary ammonium accumulation seen with chronic hyperkalemia in the present study. Whether chronic hyperkalemia may influence other ammonium transport processes in the loop segment, such as secretion of ammonium into the proximal straight tubule or diffusion of $\mathrm{NH}_{4}^{+}$across the thin ascending $\operatorname{limb}(13,14,29)$, is not known.

An important consequence of the effect of chronic hyperkalemia to impair medullary ammonium accumulation is a decrease in the driving force for secretion of ammonium into the medullary collecting ducts. Collecting ducts synthesize relatively little ammonium $(13,23,30,31)$, so that secretion of ammonium into collecting ducts occurs by transepithelial transport. Studies with isolated, perfused tubules have demonstrated that secretion of ammonium in all segments of the collecting duct occurs by the combination of $\mathrm{NH}_{3}$ diffusion and active $\mathrm{H}^{+}$secretion $(13,14,31)$. The transepithelial $\mathrm{NH}_{3}$ concentration difference that drives secretion of ammonium into the medullary collecting ducts in vivo is largely the result of the high concentrations of ammonium generated in medullary interstitial fluid by countercurrent multiplication $(14,15)$. The present study shows that chronic hyperkalemia reduced both the $\mathrm{NH}_{3}$ concentration difference across the medullary collecting duct and the rate of collecting duct ammonium secretion. In addition, the decrease in the transepithelial $\mathrm{NH}_{3}$ concentration difference was due entirely to a decrease in $\mathrm{NH}_{3}$ concentration in the medullary interstitial fluid, with no change in $\mathrm{NH}_{3}$ concentration in the collecting duct lumen. These observations support the view that an effect of $\mathrm{K}^{+}$to impair countercurrent trapping of ammonium through inhibition of $\mathrm{NH}_{4}^{+}$ absorption in the medullary thick ascending limb may play an important role in reducing collecting duct ammonium secretion and urinary ammonium excretion during chronic hyperkalemia. Although a decrease in the transepithelial $\mathrm{NH}_{3}$ con- centration difference and net ammonium secretion was demonstrated only for the terminal inner medullary collecting duct, we believe that the impairment of countercurrent multiplication would reduce interstitial ammonium levels along the entire medullary axis, resulting in impaired secretion of ammonium along both outer and inner medullary collecting duct segments.

In addition to chronic hyperkalemia, several other conditions have been identified in which regulation of ammonium accumulation in the renal medulla appears to contribute to the control of urinary ammonium excretion. In chronic metabolic acidosis, an increase in medullary ammonium accumulation increases the $\mathrm{NH}_{3}$ concentration difference across the medullary collecting duct and consequently increases collecting duct ammonium secretion (15). The increase in medullary ammonium accumulation in chronic acidosis can be attributed both to an increase in delivery of ammonium to the loop of Henle from the proximal tubule (13) and to an adaptive increase in the capacity of the medullary thick ascending limb to absorb ammonium (32). In selective aldosterone deficiency, a decrease in medullary ammonium trapping, possibly due to the associated hyperkalemia, likely contributes to the impairment in medullary collecting duct ammonium secretion and urinary ammonium excretion (8). Conversely, in humans with chronic potassium depletion due to primary aldosteronism, an increase in medullary ammonium levels secondary to stimulation of $\mathrm{NH}_{4}^{+}$absorption in the medullary thick ascending limb was invoked to explain why partitioning of ammonium between urine and renal venous blood was maintained despite an increase in urine $\mathrm{pH}$ (33). Finally, a direct correlation between the corticomedullary ammonium gradient and the rate of urinary ammonium excretion has been observed in rats in several conditions, including water diuresis and deprivation (27), $\mathrm{NaHCO}_{3}$ loading $(27,34)$, and osmotic diuresis $(34,35)$. These observations suggest that the transport processes responsible for medullary ammonium accumulation play an important role in controlling urinary ammonium excretion. As discussed above, regulation of ammonium absorption in the medullary thick ascending limb may be an important element underlying the relationship between medullary ammonium accumulation, collecting duct ammonium secretion, and urinary ammonium excretion.

In addition to the decrease in medullary interstitial $\mathbf{N H}_{3}$ concentration, other factors may contribute to the decrease in collecting duct ammonium secretion in the high- $\mathrm{K}^{+}$rats. In the hyperkalemic rats, no net transport of ammonium was observed along the collecting duct despite the presence of a transepithelial $\mathrm{NH}_{3}$ concentration difference favoring $\mathrm{NH}_{3}$ secretion. Two possible explanations for this observation are: $(a)$ that net secretion of ammonium occurred, but at a rate too small to detect due to the variability inherent in calculating and comparing base and tip [Am]/(TF/P $)_{\text {In }}$, and $(b)$ that diffusional entry of $\mathrm{NH}_{3}$ was opposed by net efflux of $\mathrm{NH}_{4}^{+}$from collecting duct lumen to medullary interstitium, resulting in no net ammonium transport. It is not known whether chronic hyperkalemia may influence $\mathrm{NH}_{4}^{+}$transport across the medullary collecting duct, or whether a high luminal or peritubular $\mathrm{K}^{+}$concentration may directly affect collecting duct ammonium secretion.

An ancillary finding in the present study was an increase in $\mathrm{pH}$ at the base and tip of the collecting duct (Table III) and in urine from the right, untouched kidney (Table II) in the high$\mathrm{K}^{+}$rats. Concurrently we observed a decrease in net entry of 
$\mathrm{NH}_{3}$ into the collecting duct, a change that by itself would be expected to diminish collecting duct $\mathrm{pH}$. The combined result of an increase in $\mathrm{pH}$ and a decrease in net ammonium secretion suggests that net $\mathrm{H}^{+}$secretion by the collecting duct was impaired in the hyperkalemic rats. Further studies of the effects of dietary $\mathrm{K}^{+}$loading on medullary collecting duct acidification will be required to test this possibility directly.

In summary, our previous demonstration that chronic hyperkalemia reduced urinary ammonium excretion but had no effect on proximal convoluted tubule ammonium secretion suggested that hyperkalemia may influence ammonium excretion through effects on medullary ammonium transport events (12). The results of the present study demonstrate directly that chronic hyperkalemia induced by dietary $\mathrm{K}^{+}$loading impairs both accumulation of ammonium in the medullary interstitial fluid and secretion of ammonium into the medullary collecting ducts. The decrease in medullary ammonium accumulation is most likely the result of impaired countercurrent multiplication of ammonium due to inhibition of ammonium absorption in the medullary thick ascending limb by high medullary $\mathrm{K}^{+}$ levels $(16,17)$. The decrease in collecting duct ammonium secretion is the result of a decrease in the $\mathrm{NH}_{3}$ concentration difference across the collecting duct that is due entirely to a fall in $\mathrm{NH}_{3}$ concentration in the medullary interstitial fluid. These findings indicate that the effect of chronic hyperkalemia to reduce urinary ammonium excretion is due at least in part to a defect in the transfer of ammonium to collecting ducts in the renal medulla.

\section{Acknowledgments}

We thank Carlton Caflisch for assistance in developing and constructing the pH microelectrodes, Galen Bevel and Cynthia Orlea for technical assistance, and Ofilia Chlamon for preparation of the manuscript.

This research was supported by National Institute of Diabetes and Digestive and Kidney Diseases (NIDDK) grant DK-30603. D. Good is the recipient of NIDDK Research Career Development Award DK01745 .

\section{References}

1. Tannen, R. L. 1977. Relationship of renal ammonia production and potassium homeostasis. Kidney Int. 11:453-465.

2. DuBose, T. D., Jr. and R. J. Alpern. 1989. Renal tubular acidosis. In The Metabolic Basis of Inherited Disease. 6th edition. C. R. Scriver, A. L. Beaudet, W. S. Sly, and D. Valle, editors. McGraw-Hill, Inc., New York. 2539-2568.

3. Tannen, R. L. 1987. Effect of potassium on renal acidification and acidbase homeostasis. Semin. Nephrol. 7:263-273.

4. Szylman, P., O. S. Better, C. Chaimowitz, and A. Rosler. 1976. Role of hyperkalemia in the metabolic acidosis of isolated hypoaldosteronism. N. Engl. J. Med. 294:361-365.

5. Hulter, H. N., L. P. Ilnicke, J. A. Harbottle, and A. Sebastian. 1977. Impaired renal $\mathrm{H}^{+}$secretion and $\mathrm{NH}_{3}$ production in mineralocorticoid-deficient glucocorticoid-replete dogs. Am. J. Physiol. 232 (Renal Fluid Electrolyte Physiol. 1):F136-F146.

6. Hulter, H. N., R. D. Toto, L. P. Ilnicki, and A. Sebastian. 1983. Chronic hyperkalemic renal tubular acidosis induced by $\mathrm{KCl}$ loading. Am. J. Physiol. 244(Renal Fluid Electrolyte Physiol. 13):F255-F264, 1983.

7. Maher, T., M. Schambelan, I. Kurtz, H. N. Hulter, J. W. Jones, and A. Sebastian. 1984. Amelioration of metabolic acidosis by dietary potassium restriction in hyperkalemic patients with chronic renal insufficiency. J. Lab. Clin. Med. 103:432-445.

8. DuBose, T. D., Jr., and C. R. Caflisch. 1988. Effect of selective aldosterone deficiency on acidification in nephron segments of the rat inner medulla. J. Clin. Invest. 82:1624-1632.
9. Sleeper, R. S., P. Belanger, G. Lemieux, and H. G. Preuss. 1982. Effects of in vitro potassium on ammoniagenesis in rat and canine kidney tissue. Kidney Int. 21:345-353.

10. Sastrasinh, S., and R. L. Tannen. 1983. Effect of potassium on renal $\mathrm{NH}_{3}$ production. Am. J. Physiol. 244(Renal Fluid Electrolyte Physiol. 13):F383F391.

11. Nagami, G. T. 1990. Effect of bath and luminal potassium concentration on ammonia production and secretion by mouse proximal tubules perfused in vitro. J. Clin. Invest. 86:32-39.

12. DuBose, T. D., Jr., and D. W. Good. 1991. Effects of chronic hyperkalemia on renal production and proximal tubule transport of ammonium in rats. Am. J. Physiol. 260 (Renal Fluid Electrolyte Physiol. 29):F680-F687.

13. Knepper, M. A., R. Packer, and D. W. Good. 1989. Ammonium transport in the kidney. Physiol. Rev. 69:179-249.

14. Good, D. W., and M. A. Knepper. 1990. Mechanisms of ammonium excretion: Role of the renal medulla. Semin. Nephrol. 10:166-173.

15. Good, D. W., C. R. Caflisch, and T. D. DuBose, Jr. 1987. Transepithelial ammonia concentration gradients in inner medulla of the rat. Am. J. Physiol. 252 (Renal Fluid Electrolyte Physiol. 21):F491-F500.

16. Good, D. W. 1987. Effects of potassium on ammonia transport by medullary thick ascending limb of the rat. J. Clin. Invest. 80:1358-1365.

17. Good, D. W. 1988. Active absorption of $\mathrm{NH}_{4}^{+}$by rat medullary thick ascending limb: Inhibition by potassium. Am. J. Physiol. 255 (Renal Fluid Electrolyte Physiol. 24):F78-F87.

18. Battilana, C. A., D. C. Dobyan, F. B. Lacy, J. Bhattacharya, P. A. Johnston, and R. L. Jamison. 1978. Effect of chronic potassium loading on potassium secretion by the pars recta or descending limb of the juxtamedullary nephron in the rat. J. Clin. Invest. 62:1093-1103.

19. Higashihara, E., J. B. Stokes, J. P. Kokko, W. B. Campbell, and T. D. DuBose, Jr. 1979. Cortical and papillary micropuncture examination of chloride transport in segments of the rat kidney during inhibition of prostaglandin production. J. Clin. Invest. 64:1277-1287.

20. Good, D. W., and G. G. Vurek. 1983. Picomole quantitation of ammonia by flow-through fluorometry. Anal. Biochem. 130:199-202.

21. Jamison, R. L. 1970. Micropuncture study of superficial and juxtamedullary nephrons in the rat. Am. J. Physiol. 218:46-55.

22. Diezi, J., P. Michoud, J. Aceves, and G. Giebisch. 1973. Micropuncture study of electrolyte transport across papillary collecting duct of the rat. Am. J. Physiol. 224:623-634.

23. Good, D. W., and M. B. Burg. 1984. Ammonia production by individual segments of the rat nephron. J. Clin. Invest. 73:602-610.

24. Good, D. W., M. A. Knepper, and M. B. Burg. 1984. Ammonia and bicarbonate transport by thick ascending limb of rat kidney. Am. J. Physiol. 247 (Renal Fluid Electrolyte Physiol. 16):F35-F44.

25. Garvin, J. L., M. B. Burg, and M. A. Knepper. 1988. Active $\mathrm{NH}_{4}^{+}$absorption by the thick ascending limb. Am. J. Physiol. 255 (Renal Fluid Electrolyte Physiol. 24):F57-F65.

26. Watts, B. A., III, and D. W. Good. 1991. Effects of $\mathrm{NH}_{4}^{+}$concentration on cell $\mathrm{pH}, \mathrm{NH}_{4}^{+}$absorption, and $\mathrm{HCO}_{3}^{-}$absorption in rat medullary thick ascending limb. Clin. Res. 39:363A. (Abstr.)

27. Packer, R. K., S. S. Desai, K. Hornbuckle, and M. A. Knepper. 1991. Role of countercurrent multiplication in renal ammonium handling: regulation of medullary ammonium accumulation. J. Am. Soc. Nephrol. 2:77-83.

28. Kinne, R., E. Kinne-Saffran, H. Schutz, and B. Scholermann. 1986. Ammonium transport in medullary thick ascending limb of rabbit kidney: involvement of the $\mathrm{Na}^{+}, \mathrm{K}^{+}, \mathrm{Cl}^{-}$-cotransporter. J. Membr. Biol. 94:279-284.

29. Flessner, M. F., S. M. Wall, and M. A. Knepper. $1990 . \mathrm{NH}_{3}$ and $\mathrm{NH}_{4}^{+}$ permeabilities of renal medullary tubule segments. Kidney Int. 37:536.

30. Wright, P. A., and M. A. Knepper. 1990. Phosphate-dependent glutaminase activity in rat renal cortical and medullary tubule segments. Am. J. Physiol. 259 (Renal Fluid Electrolyte Physiol. 28):F961-F970.

31. Flessner, M. F., and M. A. Knepper. 1990. Ammonium transport in collecting ducts. Miner. Electrolyte Metab. 16:299-307.

32. Good, D. W. 1990. Adaptation of $\mathrm{HCO}_{3}^{-}$and $\mathrm{NH}_{4}^{+}$transport in rat MTAL: Effects of chronic metabolic acidosis and $\mathrm{Na}^{+}$intake. Am. J. Physiol. 258 (Renal Fluid Electrolyte Physiol. 27):F1345-F1353.

33. Tizianello, A., G. Garibotto, C. Robaudo, S. Saffioti, R. Pontremoli, M. Bruzzone, and G. Deferrari. 1991. Renal ammoniagenesis in humans with chronic potassium depletion. Kidney Int. 40:772-778.

34. Robinson, R. R., and E. E. Owen. 1965. Intrarenal distribution of ammonia during diuresis and antidiuresis. Am. J. Physiol. 208:1129-1134.

35. Stern, L., K. A. Backman, and J. P. Hayslett. 1985. Effect of cortical-medullary gradient for ammonia on urinary excretion of ammonia. 1985. Kidney Int. 27:652-661. 